Annals of
Neurosciences
Ann Neurosci 2018;25:38-45

DOI: $10.1159 / 000484165$
Received: July 12, 2017

Accepted: October 11, 2017

Published online: November 20, 2017

\title{
Effect of Add-On Yoga on Cognitive Functions among Substance Abusers in a Residential Therapeutic Center: Randomized Comparative Study
}

\author{
Ananda Gaihre Sasidharan K. Rajesh \\ Department of Psychology, Swami Vivekananda Yoga Anusandhana Samsthana, Bengaluru, India
}

\section{Keywords}

Yoga $\cdot$ Cognition $\cdot$ Exercise $\cdot$ Substance Abusers

\begin{abstract}
Background: Chronic vulnerability characterizes substance abuse disorder with consequent relapse. The process of abstinence depends on cognitive recovery. Hence, behavioral intervention should account for cognitive dimension of substance abusers. Recent studies highlight yoga-based intervention as a promising add-on therapy for treating and preventing addictive behaviors. Purpose: The study aimed to evaluate the efficacy of a yoga-based intervention as an addon in enhancing cognitive functions, compared with physical exercise to newly admitted substance abusers seeking an inpatient treatment program. Methods: The study was a single-blind, randomized, comparative design that included 96 male participants, between 18 and 40 years in a residential rehabilitation treatment unit. Partakers in the yoga or physical exercise group received supervised daily training for 12 weeks, in addition to standard rehabilitation treatment. Raters blind to the study assessed the patients on digit span task, cancellation test, and Stroop tests at the baseline and following 12 weeks of intervention. Results: A significant enhancement in digit forward (yoga $-p<0.0005, \mathrm{~d}=0.81$; ex-
\end{abstract}

ercise $-p<0.0005, \mathrm{~d}=0.73$ ), digit backward (yoga $-p<$ $0.0005, d=0.88$; exercise $-p<0.0005, d=0.58$ ), and letter cancellation test scores (yoga $-p<0.0005, \mathrm{~d}=1.31$; exercise $-p<0.0005, d=1.4$ ) were observed in both the yoga and the exercise groups. Stroop word and color task scores were seen significantly higher following yoga $(p<0.005, d=$ $0.74 ; p<0.005, \mathrm{~d}=1.13)$ and exercise $(p<0.0005, \mathrm{~d}=0.62$; $p<0.0005, \mathrm{~d}=0.61$ ). Furthermore, Stroop color-word test showed significant enhancement after yoga $(p<0.0005, \mathrm{~d}=$ $1.10)$ and exercise $(p<0.0005, d=0.42)$, with degree of variation higher in the yoga group. Conclusion: Our results suggest that the add-on yoga or exercise-based intervention show enhancement of cognitive functions. These findings provide the utility of yoga and exercise-based intervention in improving cognitive functions among substance abusers. Furthermore, rigorous trials are needed to explore the potential long-term effects of these procedures.

(c) 2017 S. Karger AG, Basel

\section{Introduction}

Substance abuse, the physically hazardous uses of various psychoactive drugs leads to spectrums of bio-psychosocial morbidities, social instability, disability, occu-

\section{KARGER}

(c) 2017 S. Karger AG, Basel

E-Mail karger@karger.com

www.karger.com/aon
Sasidharan K. Rajesh

Department of Psychology, S-VYASA Yoga University

No. 19, Eknath Bhavan, Gavipuram Circle, K.G. Nagar

Bengaluru 560-019 (India)

E-Mail rajesheskay@svyasa.org 
pational crisis, and ultimate health care burden. Findings of the World Drug Report 2015 projected that 1 out of 20 people between the age range of 15 and 64 years used an illicit drug in 2013. Furthermore, about 187,100 drug-related demises were reported in 2013 [1]. In Nepal, studies have shown a significant rise with 91,534 substance users in 2013, which is nearly of double of that 46,309 in 2007 [2]. The upsurge may be due to the government policy [3], society, and the family tolerance [4] toward substance use.

Cognitive impairments are highly prevalent in persons seeking treatment for substance use disorders (SUDs) [57]. Substance dependence induces cognitive impairments that mainly affects the abilities of inhibition [5], coordination of storage, and manipulation of information [6] and visuospatial functions [7]. Despite the demonstrated efficacy of different treatments, SUDs are characterized by chronic vulnerability to relapse after detoxification; on an average, $50 \%$ relapse within 1 year [8]. Results indicate that abstinence in the behavioral intervention process appear to depend on cognitive abilities. Furthermore, the literature suggests that it is essential to take into account the cognitive dimension of substance abusers to adapt and fully benefit from the treatment proposed in addiction medicine units [9].

Recent findings show yoga-based intervention as a promising complementary therapy for treating and preventing addictive behaviors [10]. Yoga in its original form consists of a system of ethical, psychological, and physical practices. Although of ancient origin, it transcends cultures and languages. Mindfulness-based relapse prevention (MBRP) program involves training the attention to experience the present moment with the intention to cultivate nonjudgmental and nonreactive states of awareness [11]. A recent study evaluated the long-term efficacy of MBRP compared with cognitive-behavioral relapse prevention and treatment as usual (TAU) [11]. The report showed a lowered risk of relapse to substance use and significantly decreased heavy drinking during a 12-month follow-up period in the MBRP group in the intervention group compared to the other 2 groups. Furthermore, literature suggests that yoga can lead to significant symptomatic improvements in psychiatric disorders, with changes in neurological pathways [12]. Prior research has shown enhancement of cognitive functions in healthy and elderly population following yoga-based intervention [13-14].

We aimed to explore the effects of add-on yoga-based intervention and physical exercise on the performance of 4 commonly used cognitive tests evaluating working memory and executive function: Stroop test, digits forward, digits backward, and the cancellation task. Stroop test assesses the ability to inhibit cognitive interference, selective attention, and conflict resolution [15]. Further, the Digit Span tasks have been widely used to evaluate span of auditory attention, immediate memory span, and working memory [16]. Furthermore, cognitive domains involved in the cancellation function includes sustained and selective attention, psychomotor speed, visual searching, and motor coordination [17]. Hence, it is hypothesized that add-on yoga-based intervention with TAU might show significant improvement in cognitive outcomes compared with those in the TAU + physical exercise. The present study is, to our knowledge, the first randomized, comparative trial to assess the effect of the yoga-based intervention on cognitive function in SUDs.

\section{Methodology}

Subjects were newly admitted substance abusers, receiving an inpatient treatment program. The focus group was from a residential rehabilitation treatment unit at Katmandu Valley, Nepal. The Center provided an in-house rehabilitation care for an average of 4 months. The inclusion criteria for this study were that the subjects were of 18-40 years of age; meet the DSM-V criteria for substance use disorder, capable of comprehending and speaking English, show sufficient stability in psychological symptoms (e.g., actively suicidal, psychotic), and a regulated substance intoxication. Subjects who have had a legal case that interfered during the study period, history of severe or ongoing violence, evidence of self-harming or suicidal ideations, any acute major psychiatric disorder, and chronic infections such as HIV and tuberculosis were excluded. The subjects did not perform baseline assessments until 3 weeks of sobriety or abstinence in which they underwent medically supervised detoxification. Eligible individuals provided written informed consent and completed the baseline assessment. Outcome assessments were conducted individually and performed by research staff blinded to treatment assignment. Following baseline assessments, the subjects were assigned randomly to the yoga intervention or physical exercise for 12 weeks, in addition to standard rehabilitation procedures at the Treatment Unit. The 96 eligible subjects were equally and randomly divided into yoga $(n=48)$ and physical exercise $(n=48)$ groups. The study was reviewed and received ethical approval (631-02/10/16) from the $\mathrm{Ne}$ pal Health Research Council Kathmandu, Nepal.

\section{Assessments}

Stroop Color-Word Test

Golden's version of Stroop color-word test was used in this study [15]. The Stroop test includes 3 time-limited (45-s) subtests (word, color, and color-word). Task 1 consisted of the words red, 
Table 1. The 90-min daily interventions practiced by yoga and physical exercise groups

\begin{tabular}{|c|c|c|c|c|c|}
\hline Yoga group practices & $\begin{array}{l}\text { Number } \\
\text { of rounds }\end{array}$ & $\begin{array}{l}\text { Time, } \\
\text { min }\end{array}$ & Physical group practices & $\begin{array}{l}\text { Number } \\
\text { of rounds }\end{array}$ & $\begin{array}{l}\text { Time, } \\
\text { min }\end{array}$ \\
\hline 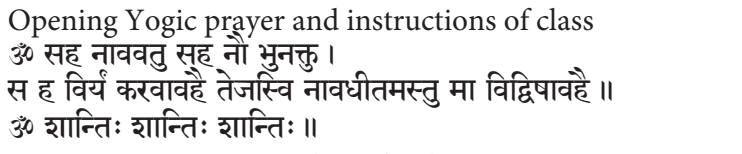 & 1 & 5 & $\begin{array}{l}\text { Opening prayer and instructions of class } \\
\text { Rehabilitation center opening prayer }\end{array}$ & 1 & 5 \\
\hline Loosening practices (Standing) & & & Loosening practices (standing) & & \\
\hline Neck movement (Greevasanchalana ) & 5 & 1 & Warm up (movement of all body parts) & 1 & 5 \\
\hline Finger movement (Angulisanchalana) & 5 & 1 & Jogging (forward, backward, side) & 3 & 5 \\
\hline Wrist rotation (Mani bandhachakra) & 5 & 1 & Jumping & 1 & 2 \\
\hline Shoulder rotation (Skandhachakra) & 5 & 1 & Jumping and clapping & 1 & 3 \\
\hline Hands twisting & 5 & 1 & Hopping & 1 & 2 \\
\hline Hip rotation (clock and anticlockwise) & 5 & 1 & Side bending & 1 & 3 \\
\hline Forward and backward bending & 10 & 1 & Forward and backward bending & 1 & 3 \\
\hline Patella (knee cap movement) & 10 & 1 & Twisting & 1 & 2 \\
\hline Toes, ankles, and fingers & 10 & 1 & Alternate toe touching & 1 & 3 \\
\hline Instant relaxation techniques & & & Side bending & 1 & 2 \\
\hline Tighten whole part of body and relax & 1 & 1 & Hands rotation & 1 & 2 \\
\hline Breathing practices & & & Drill walking & 1 & 3 \\
\hline Hand in and out movement (Hasta ayamasvasanam) & 5 & 1 & Brisk walking & 1 & 3 \\
\hline Hand stretch breathing (Hasta vistarasvasanam) & 5 & 1 & Running (35 meter) & 10 & 5 \\
\hline Ankle stretch breathing (Gulphavistarasvasanam) & 5 & 1 & Sitting exercise & & \\
\hline Rabbit breathing (Sasankhasana breathing) & 5 & 1 & Sitting twisting exercise (left and right side) & 1 & 2 \\
\hline Tiger breathing (Vyagraha breathing) & 5 & 1 & Sitting side bending by hand rising & 1 & 3 \\
\hline Bridge posture, breathing (Setubandhasvasanam) & 5 & 1 & Supine exercise & & \\
\hline Sun salutation with opening prayer (10 counts) & 10 & 10 & Cycling & 1 & 3 \\
\hline Hand rising posture (Hastuttanasana) & & & Alternate leg rising & 1 & 3 \\
\hline Hand to feet posture (Padahastasana) & & & Both legs rising & 1 & 3 \\
\hline Horse riding posture (Aswosanchalanasana) & & & Rocking and rolling & 1 & 3 \\
\hline Plank posture (Chaturdandasana) & & & Face up supine bridge & 1 & 3 \\
\hline Cobra posture (Bhujangasana) & & & Supine abdominal exercise & 1 & 2 \\
\hline Mountain posture (Parvatasana) & & & Prone exercise & & \\
\hline Quick relaxation techniques & 1 & 3 & Push up & 2 & 3 \\
\hline Feel the breath & & & Prone alternating leg lifts & 1 & 3 \\
\hline Synchronized the breath with abdominal breathing & & & Prone alternate knee bend & 1 & 3 \\
\hline Positive thinking & & & Supine rest & 1 & 10 \\
\hline Asanas (postures) & & & Closing prayer & 1 & 1 \\
\hline Standing postures & & & ॐ0 सर्वे भवन्तु सुखिवः सर्वे सन्तु निरामयाः। & & \\
\hline Tree posture (Vrikshasana) & 5 & 1 & सर्वे भद्राणि पइयन्तु मा कश्चित् दु :खभाग्भवेत्॥ & & \\
\hline Half waist rotation posture (Ardhakatichakrasana) & 5 & 1 & ॐ० शान्तिः शान्तिः शान्तिः॥ & & \\
\hline Triangle posture (Trikonasana) & 5 & 1 & & & \\
\hline Half wheel posture (Ardhachakrasana) & 5 & 1 & & & \\
\hline Warrior postures (series 1,2,3,4) (Birbhadrasana 1,2,3,4) & 5 & 1 & & & \\
\hline Sitting postures & & & & & \\
\hline Thunderbolt - Diamond (Vajrasana) & 5 & 2 & & & \\
\hline Camel posture (Ustrasana) & 5 & 1 & & & \\
\hline Posterior stretches (Paschimottansana) & 5 & 1 & & & \\
\hline Spinal twist posture (Ardhamatsyendrasana) & 5 & 1 & & & \\
\hline Cow face posture (Gomukhasana) & 5 & 2 & & & \\
\hline Twisted pose (Vakrasana) & 5 & 1 & & & \\
\hline Rabbit posture (Shashankasana) & 5 & 2 & & & \\
\hline Supine postures & & & & & \\
\hline Shoulder stand posture (Sarvangasana) & 5 & 1 & & & \\
\hline Fish posture (Matsyasana) & 5 & 1 & & & \\
\hline Bridge posture (Setubandasana) & 5 & 1 & & & \\
\hline Folded cross leg lumbar stretches & 5 & 1 & & & \\
\hline Boat posture (Naukasana) & 5 & 1 & & & \\
\hline
\end{tabular}


Table 1. (continued)

\begin{tabular}{|c|c|c|c|c|}
\hline Yoga group practices & $\begin{array}{l}\text { Number } \\
\text { of rounds }\end{array}$ & $\begin{array}{l}\text { Time, Physical group practices } \\
\text { min }\end{array}$ & $\begin{array}{l}\text { Number } \\
\text { of rounds }\end{array}$ & $\begin{array}{l}\text { Time, } \\
\min \end{array}$ \\
\hline \multicolumn{5}{|l|}{ Prone posture } \\
\hline Bow posture (Dhanurasana) & 5 & 1 & & \\
\hline Grasshopper posture (Salabhasana) & 5 & 1 & & \\
\hline Cobra posture (Bhujangasana) & 5 & 1 & & \\
\hline Crocodile posture (Makarasana) & 5 & 2 & & \\
\hline \multicolumn{5}{|l|}{ Deep relaxation technique } \\
\hline \multicolumn{5}{|l|}{ Relax whole parts of the body } \\
\hline (lower, middle, upper parts) & 1 & 10 & & \\
\hline \multicolumn{5}{|l|}{ Pranayama } \\
\hline \multicolumn{5}{|l|}{ Breathing with forceful exhalation with passive } \\
\hline \multicolumn{5}{|l|}{ Breathing with rapid inhalation \& exhalation } \\
\hline (Bhastrika) & 3 & 3 & & \\
\hline Cooling pranayama (Sitkari, Sitali, Sadanta) & 3 & 3 & & \\
\hline Honey bee sound (Bhramari) & 3 & 3 & & \\
\hline Alternate nostril breathing (Nadisuddhi) & 7 & 3 & & \\
\hline \multicolumn{5}{|l|}{ Meditation } \\
\hline $\begin{array}{l}\text { Om meditation (Aum Dhyana) } \\
\text { Cyclic meditation (Avartan Dhyana) }\end{array}$ & & 20 & & \\
\hline $\begin{array}{l}\text { Closing prayer } \\
\text { ॐ सर्वे भवन्तु सुखिवः सर्वे सन्तु निरामयाः। } \\
\text { सर्वे भद्राणि पइयन्तु मा कश्वित् दुःखभाग्भवेतू॥ } \\
\text { ॐ० शान्तिः इान्तिः इान्तिः॥ }\end{array}$ & 1 & 1 & & \\
\hline $\begin{array}{l}\text { Yoga and physical exercise session } 6 \text { days per/week } \\
\text { Om meditation and cyclic meditation every friday }\end{array}$ & & & & \\
\hline
\end{tabular}

green, and blue in random order printed in black ink (capital letters) on the white sheet of paper. The subjects were asked to read the list of words. Next, subjects were presented with a list of "XXXX"s that differs in ink color (e.g., XXXX in red, blue, or green ink). The individual was asked to name the color of the ink for each "XXXX"s. The final page is the color-word task on which the individual is shown the names of colors printed incongruent ink colors (e.g., the word "RED" in green ink). The participants are asked to call out the color of the ink rather than the word. Each subtest contains 100 items, presented in 5 columns of 20 items. Subjects were instructed to read down the columns starting with the top word in the leftmost column. The item named last on each stimulus card after 45 -s was noted. Stroop possesses adequate testretest reliabilities of 0.89 (word), 0.84 (color), and 0.73 (colorword).

\section{WAIS-R Digit Span Task [16]}

The test consists of 2 parts, digit forward and digit backward. The digit span task assesses attention, immediate memory span, and working memory. The participants were administered the test following the standardized instructions. The subjects listened to verbally present digits' sequences (e.g., 6-9-4) at a rate of one per second. After every sequence, the participants were asked to reproduce the string in the same order as given by the examiner (forward span; e.g., 6-9-4), or in the reverse order (backward span; e.g.,-4-9-6). The digit sequences consist of a randomly picked number from 0 to 9 , so that no calculation or serial association can be performed. The first span includes 2 numbers. The consecutive span has one more digit added and so on until the last span included 9 digits in forward test while 2-8 digits in the backward test. Furthermore, in each trail, no repetition of the digit was present in the sequence. Each span size has 2 trials. The score was the total number of correct trials, before failing 2 consecutive trials at any one span size or when a full digit number is repeated successfully. Relatively stable threshold value was found to be .83 .

\section{Six Letter Cancellation Task}

Cancellation tasks [17] are widely used to evaluate sustained and selective attention, psychomotor speed, visual searching, and motor coordination [18]. The cancellation worksheet consists of the 6 target capital letters printed at the top of working section. Subjects required to search and mark as fast and as accurately as possible, target letters arranged randomly in 22 rows and 14 columns. After 90s, the task was interrupted. Subjects were instructed regarding 2 possible strategies to cancel target letters: focus on all target letters at once or select a single target letter at a time. Further, it is suggested that they can adapt different searching strategies (randomized or organized searching: horizontal scanning, for example, from left to right, or vertical scanning) according to their own choice. The total cancellation attempted and incorrect canceled targets are recorded. The net score is calculated by deducting 
the incorrect cancellations from the total cancellations attempted. The 6 letter cancellation reported adequate amount of stability over time .78 [19].

\section{Intervention}

The yoga-based program and physical exercise were supervised by a trained yoga therapist and a physical instructor at a rehabilitation center. The training included weekly 6 sessions of 90 -min duration over 12 weeks. The sessions were conducted in the morning 6.30-8.00 a.m. There were structured protocols for the exercise and yoga tasks, criteria for progression, and guidelines for durations and levels. Intervention programs began at a light intensity and gradually increased over the first month of the intervention. Training sessions were administered in groups whereas each group had 8-15 participants and 1 trainer. Also, participants received standard rehabilitation treatment such as psychosocial intervention, educational lectures, and recreation at the Treatment Unit. The Yoga module was based on concepts from ancient yoga scriptures and developed specifically for SUDs. Yoga module consisted of various components such as loosening practices, sun salutations, yogic postures (asanas), breathing exercises, regulation of breath (pranayama), comfortable dwelling of the mind in a single thought with awareness while practicing unbroken concentration (meditation) and relaxation techniques. The exercise program included loosening warm-up, moderate aerobics which included types of walking (drill, brisk) and jogging (forward, backward, side), stretching module to enhance flexibility, and strengthening exercises. Detailed practice list is shown in Table 1.

\section{Results}

The trial profile is shown in Figure 1. Of 96 recruited participants, data for 87 substance abusers were available: yoga $(n=44)$ and physical exercise $(n=43)$ for final analysis. The reason for dropout is enlisted in the trail profile. All statistical analyses were performed using the computing environment $\mathrm{R}$ (version 3.4.0). Descriptive statistics is expressed as mean $\pm \mathrm{SD}$ for continuous variables. Categorical variables are presented as frequencies (percentage). The normality of quantitative variables was determined using Shapiro-Wilk test and visual inspection of the normal Q\&Q plot. Univariate statistics on differences between baseline variables were calculated by the $\chi^{2}$ test, the Mann-Whitney test or Student $t$ test. All analyses, statistically, significance was considered at $p<0.05$. Table 2 summarizes sociodemographic, and outcome measures at baseline and no significant differences were observed at baseline in age, education, marital status, years of substance abuse, type of drug addiction, and outcome parameters between the 2 groups.

Table 3 includes within-group comparisons on yoga and exercise groups on outcomes following 3 months.

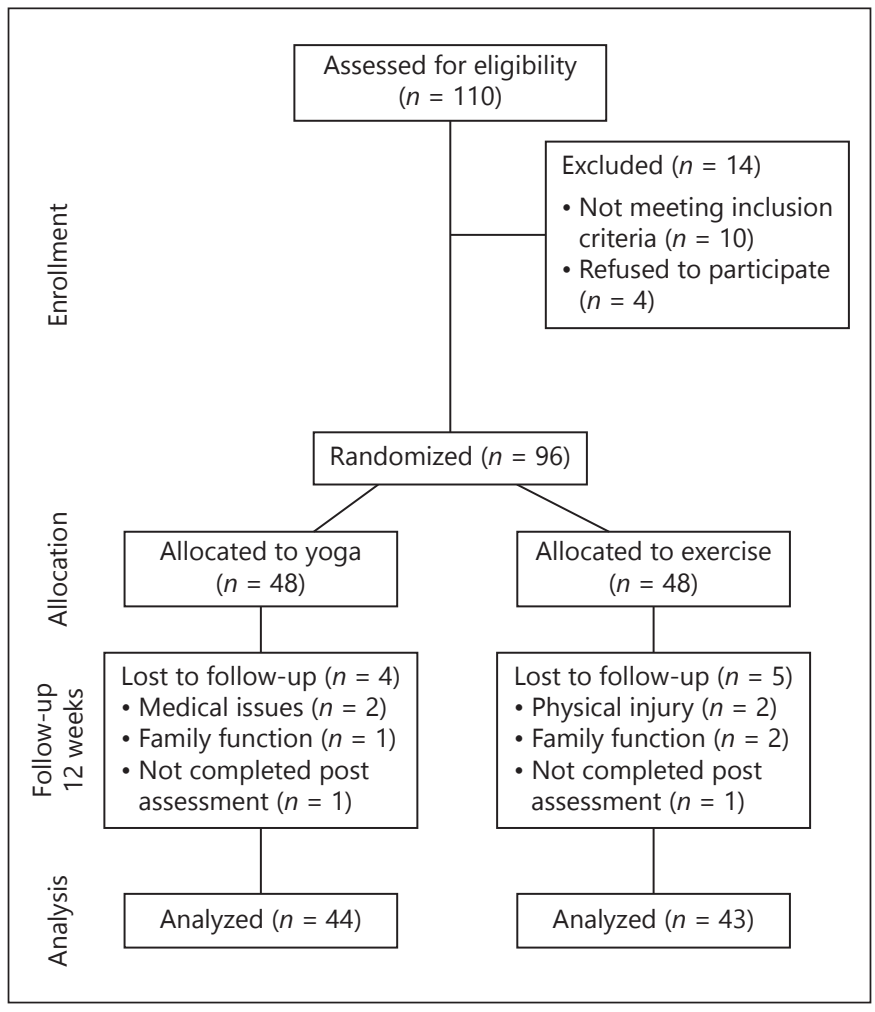

Fig. 1. Trail profile.

No outliers were detected as assessed by inspection of a box plot for a value greater than 1.5 box length. The assumption of normality was not violated on different scores, as assessed by Shapiro-Wilk tests and visual inspection of the normal Q\&Q plot. A paired sample $t$ test was used to determine whether there was a statistically significant mean difference of pre- and post-yoga intervention. Further, effect size, Cohen's d, were calculated for a paired-samples $t$ test by dividing the mean difference by the SD of the difference (Cohen, 1988). Significant enhancement in digit forward was observed in both the yoga $(p<0.0005, \mathrm{~d}=0.81)$ and the exercise group $(p<0.0005, \mathrm{~d}=0.73)$. Post-yoga intervention shows differences on digit backward, namely statistically significant increased mean in yoga $(p<0.0005, \mathrm{~d}=$ $0.88)$ and exercise $(p<0.0005, \mathrm{~d}=0.58)$. The magnitude of change was higher in the yoga group. Furthermore, on the cancellation task, a significant increase was noted in yoga $(p<0.0005, \mathrm{~d}=1.31)$ and exercise group $(p<$ $0.0005, \mathrm{~d}=1.4)$. The results from the Stroop word and color tests were significantly greater post compared with their respective pre-scores following yoga $(p<$ $0.005, \mathrm{~d}=0.74 ; p<0.005, \mathrm{~d}=1.13)$ and exercise $(p<$
Gaihre/Rajesh 
Table 2. Baseline characteristics of the yoga and exercise groups

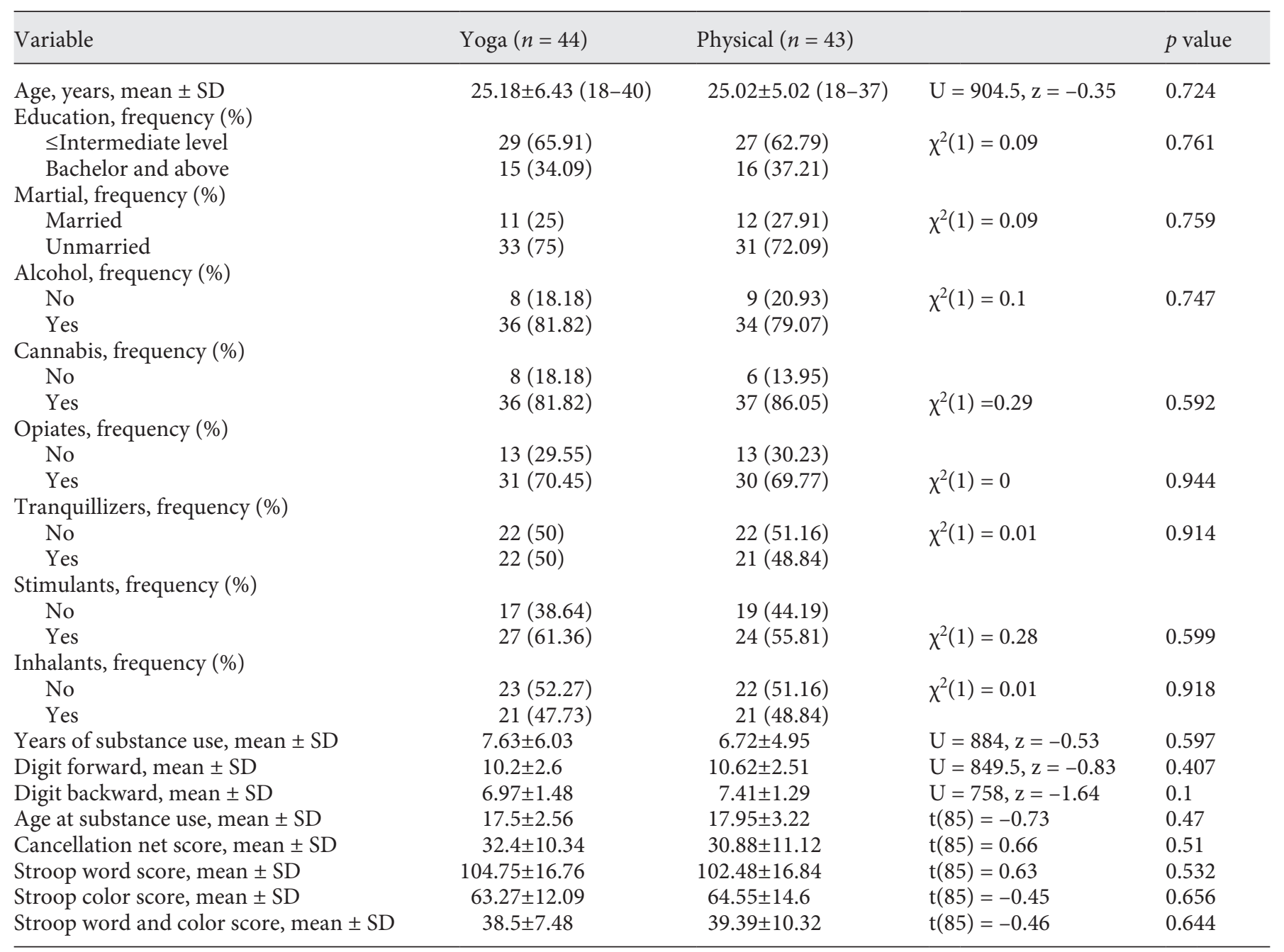

$0.0005, \mathrm{~d}=0.62 ; p<0.0005, \mathrm{~d}=0.61)$. The degree of variation was higher in the yoga group. Furthermore, significant enhancement was seen in Stroop color-word test after yoga $(p<0.0005, \mathrm{~d}=1.10)$ and exercise $(p<$ $0.0005, \mathrm{~d}=0.42)$, with differences high in yoga group following 3 months.

Differences between the yoga and physical exercise groups were analyzed using independent samples $t$ test, and are summarized in Table 4 . The homogeneity of variance is not violated as assessed by Levene's test for equality variances. However, when the changes in the parameters assessed were compared, there were no significant differences between the yoga and exercise group in any of the assessed parameters.

Yoga for Cognitive Functions among Substance Abusers

\section{Discussion}

To our knowledge, this is the first 2 arm parallel group randomized comparative clinical study evaluating the add-on effect of yoga or physical exercise on cognitive function among people with substance abuse problem. The participants were recruited from a rehabilitation center providing a therapeutic environment for detoxification to SUDs. Tasks of cognitive function, including selective attention, response inhibition, and working memory are major important risk factors for recovery and relapse for SUDs. The findings of the unblinded treatment and blinded outcome assessment study of 12 weeks period suggest that add-on yoga or physical exercise-based intervention achieved significant enhancement in response in- 
Table 3. Comparison of cognitive profiles in yoga and physical exercise groups following 12 weeks of intervention

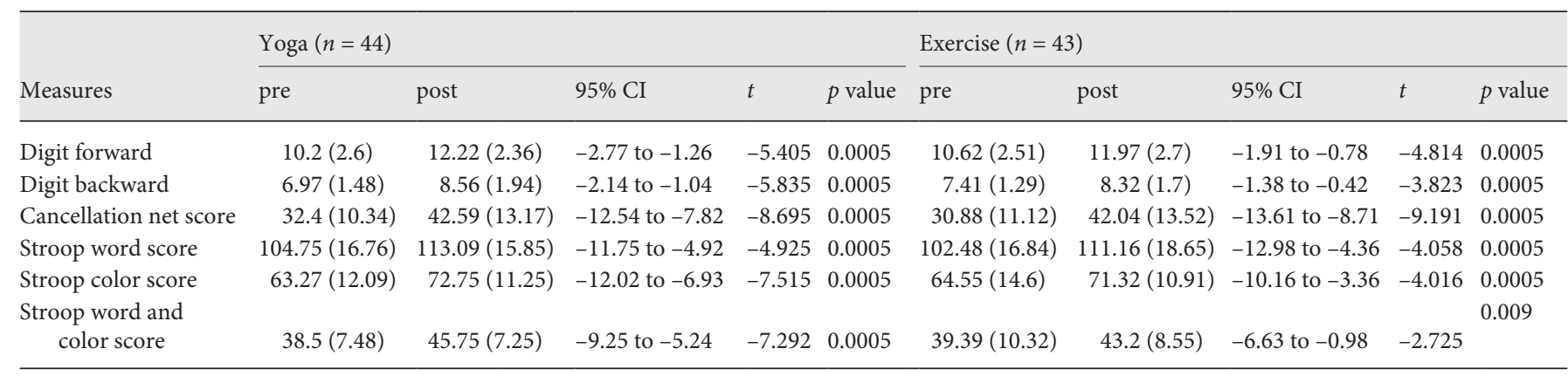

Table 4. Mean group comparisons of scores between pre-test and 12 weeks of post intervention

\begin{tabular}{|c|c|c|c|c|}
\hline Variable & $\begin{array}{l}\text { Yoga }(n=44), \\
\text { mean } \pm \mathrm{SD}^{*}\end{array}$ & $\begin{array}{l}\text { Exercise }(n=43) \\
\text { mean } \pm \mathrm{SD}^{*}\end{array}$ & $t$ value & $p$ value \\
\hline Digit forward & $-2.02 \pm 2.48$ & $-1.34 \pm 1.83$ & $\mathrm{t}(85)=-1.44$ & 0.154 \\
\hline Cancellation net score & $-10.18 \pm 7.76$ & $-11.16 \pm 7.96$ & $t(85)=0.58$ & 0.562 \\
\hline Stroop word score & $-8.34 \pm 11.23$ & $-8.67 \pm 14.01$ & $\mathrm{t}(85)=0.12$ & 0.903 \\
\hline Stroop color score & $-9.47 \pm 8.36$ & $-6.76 \pm 11.04$ & $\mathrm{t}(85)=-1.29$ & 0.2 \\
\hline
\end{tabular}

* Mean scores were computed as differences between post-test and pre-test intervention.

hibition, immediate memory span, working memory, and sustained and selective attention. Improvements due to yoga and physical exercise were not significantly different.

Our results are in-line with previous studies with regards to the increase in cognitive function following a yoga and exercise-based intervention [20-24]. Study has shown high level of physical activity as a significant protection against cognitive decline [21]. Further, this is consistent with a study of home-based exercise intervention showing similar improvement in global cognitive measures for subjects at risk for cognitive decline [22]. Yoga-based techniques have demonstrated positive influence on neuropsychological functions such as selective and executive function [23]. Furthermore, results imply a positive effect, especially on attention, memory, verbal fluency, and cognitive flexibility [24]. Use of illicit substance was linked to structural brain changes with consistent reports of hippocampal volume deficits, which alter cognitive function [2526]. Exercise training is effective at reversing hippocampal volume loss in late adulthood, which was accompanied by improved memory function [27]. Further, a pilot study on yoga intervention as an add-on lifestyle practice on elderly adults has shown increase in the volume of bilateral hippo- campus [28]. Reversing of hippocampal volume may be a potential mechanism by which practice of exercise or yoga enhanced cognitive function among SUDs.

The methodological shortcoming of this study was the absence of a control group, raising the possibility that the observed effects are not due to the interventional program by itself, but reflect normal recovery due to 12 weeks of sobriety. Future studies should include diagnostic evaluation of cognitive status to understand individuals with cognitive impairment.

Our results suggest that the add-on yoga or exercisebased intervention has shown an enhancement of cognitive functions. Yoga appears to be as good as physical exercise. A future study should determine whether an approach combining or integrating yoga and physical exercise would render more benefits than yoga or physical exercise alone. The clinical application of findings is noteworthy, as enhanced cognitive functions related to executive function domains will be a mediating factor in promoting wellbeing and prevention of relapse. Further rigorous trials are needed to explore the long-term effect and its implication in the relapse prevention and to explore the underlying mechanisms. 


\section{Acknowledgments}

We thank Prof. T.M. Srinivasan for his insightful feedback on earlier versions of this paper. We thank the participants of the rehabilitation center in the Kathmandu valley in Nepal. We are grateful to the anonymous reviewers for interesting comments and encouragements. We also thank Dr. Binod Ghimire, Dr. Yangjan Gaihre, Kamal Gaihre, and Yagya Gaihre for their assistance with data collection.

\section{Disclosure Statement}

The authors have no conflicts of interest to declare.

\section{Source(s) of Support}

This research received no specific grant from any funding agency in the public, commercial, or not-for-profit sectors.

\section{Authorship Contributions}

A.G.: participated in the study design, data collection, analysis and interpretation of data, and drafting the manuscript S.K.R.: participated in study design, study supervision, statistical analysis, and interpretation of data, as well as drafting the manuscript and revising the final paper. This article complies with International Committee of Medical Journal editor's uniform requirements for manuscript.

\section{References}

1 United Nations Office on Drugs and Crime: World Drug Report 2015. Vol. 2013, United Nations Publication, Sales No. E. 15.XI.6, 2015.

2 Central Bureau of Statistics: Survey report on current hard drug users Nepal, Nepal health Ministry, Kathmandu, 2069.

3 Timsinha S, Kar SM, Agrawal P: Drug abuse and alcohol consumption as a social habit in Nepal. Medico-Legal Updat 2011;11:42-43.

4 Shrestha NM: Alcohol and drug abuse in $\mathrm{Ne}$ pal. Br J Addict 1992;87:1241-1248.

5 Smith JL, Mattick RP, Jamadar SD, Iredale JM: Deficits in behavioural inhibition in substance abuse and addiction: A meta-analysis. Drug Alcohol Depend 2014;145:1-33.

-6 Bechara A, Martin EM: Impaired decision making related to working memory deficits in individuals with substance addictions. Neuropsychology 2004;18:152-162.

7 Kübler A, Murphy K, Garavan H: Cocaine dependence and attention switching within and between verbal and visuospatial working memory. Eur J Neurosci 2005;21:1984-1992.

8 McLellan AT, Lewis DC, O’Brien CP, Kleber HD: Drug dependence, a chronic medical illness: implications for treatment, insurance, and outcomes evaluation. JAMA 2000;284: 1689-1695.

-9 Bernardin F, Maheut-Bosser A, Paille F: Cognitive impairments in alcohol-dependent subjects. Front Psychiatry 2014;5:78.

10 Khanna S, Greeson JM: A narrative review of yoga and mindfulness as complementary therapies for addiction. Complement Ther Med 2013;21:244-252.
11 Bowen S, Witkiewitz K, Clifasefi SL, Grow J, Chawla N, Hsu SH, et al: Relative efficacy of mindfulness-based relapse prevention, standard relapse prevention, and treatment as usual for substance use disorders: a randomized clinical trial. JAMA Psychiatry 2014;71: 547-556.

12 Varambally S, Gangadhar BN: Yoga: a spiritual practice with therapeutic value in psychiatry. Asian J Psychiatr 2012;5:186-189.

-13 Hariprasad VR, Koparde V, Sivakumar P, Varambally S, Thirthalli J, Varghese M, Basavaraddi IV, Gangadhar BN: Randomized clinical trial of yoga-based intervention in residents from elderly homes: effects on cognitive function. Indian J Psychiatry 2013;55:S357S363.

14 Chiesa A, Calati R, Serretti A: Does mindfulness training improve cognitive abilities? A systematic review of neuropsychological findings. Clin Psychol Rev 2011;31:449-464.

15 Golden CJ: Stroop Color and Word Test: A manual for clinical and experimental uses. Stoelting Chicago; 1978;1-46.

16 Wechsler D: Wechsler adult intelligence scale-Fourth Edition (WAIS-IV). San Antonio, NCS Pearson, 2008.

17 Uttl B, Pilkenton-Taylor C: Letter cancellation performance across the adult life span. Clin Neuropsychol 2001;15:521-530.

18 Lezak MD, Howieson D, Loring D: Neuropsychological Assessment, ed 5. Oxford, Oxford University Press, 2012.

-19 Pradhan B, Nagendra HR: Normative data for the letter-cancellation task in school children. Int J Yoga 2008;1:72-75.
20 Gothe NP, Keswani RK, McAuley E: Yoga practice improves executive function by attenuating stress levels. Biol Psychol 2016;121: 109-116.

21 Barnes JN: Exercise, cognitive function, and aging. Adv Physiol Educ 2015;39:55-62.

22 Suzuki T, Shimada H, Makizako H, Doi T, Yoshida D, Ito $\mathrm{K}$, et al: A randomized controlled trial of multicomponent exercise in older adults with mild cognitive impairment. PLoS One 2013;8:e61483.

23 Gothe NP, Kramer AF, Mcauley E: The effects of an 8-week hatha yoga intervention on executive function in older adults. J Gerontol A Biol Sci Med Sci 2014;69:1109-1116.

24 Moore A, Malinowski P: Meditation, mindfulness and cognitive flexibility. Conscious Cogn 2009;18:176-186.

25 Filbey FM, McQueeny T, Kadamangudi S, Bice C, Ketcherside A: Combined effects of marijuana and nicotine on memory performance and hippocampal volume. Behav Brain Res 2015;293:46-53.

26 Sullivan EV, Marsh L, Mathalon DH, Lim KO, Pfefferbaum A: Anterior hippocampal volume deficits in nonamnesic, aging chronic alcoholics. Alcohol Clin Exp Res 1995;19:110-122.

27 Erickson KI, Voss MW, Prakash RS, Basak C Szabo A, Chaddock L, et al: Exercise training increases size of hippocampus and improves memory. Proc Natl Acad Sci 2011;108:3017-3022.

28 Hariprasad V, Varambally S, Shivakumar V, Kalmady SV, Venkatasubramanian G: Yoga increases the volume of the hippocampus in elderly subjects. Indian J Psychiatry 2013; 55:S394-S396. 